\title{
Assessing Learners' Perceptions and Experiences in Distance Education - A Case Study of LAUTECH Open and Distance Learning Centre (LODLC)
}

\author{
A. T. Akindele, N. O. Akande, M. O. Fajobi, H. B. Olagoke, O. A. Ajagbe, and T. A. Badmus
}

\begin{abstract}
Open and Distance Education (ODE) has proven to be a viable alternative for teaching and learning with more inherent benefits compared to the traditional model of education. This mode of teaching and learning aimed at eradicating the challenges of the face-to-face mode of learning such as distance, age, work schedules, limited access and other factors that have made the face-to-face mode of learning rigid. ODE flexibility is evidenced in the ability of learners to learn ubiquitously at their own pace, anywhere, anytime using smartphones, laptops and desktop computers. As ODE grows and expands, the need to review its conceptual foundations, approaches and also to receive feedback from learners, employers and other stakeholders are becoming more imperative. This study employed an investigative approach via the use of online survey forms to elicit pertinent information regarding the learners' perceptions and experiences at Ladoke Akintola University of Technology (LAUTECH) Open and Distance Learning Centre (LODLC). A total number of 2362 LODLC students participated in the online survey out of a total learners' population of about $5,000.54 \%$ of the respondents confirmed the adequacy of the LMS and the course material modules with more than $60 \%$ being able to easily access and download course materials from the LMS, $57 \%$ of the respondents rated the e-tutors to be effective knowledge facilitators while $60 \%$ believed the e-tutors stimulated learners' interest by providing satisfactory answers to questions asked. This information amongst others will help administrators and management of LODLC programmes to make informed decisions about the conduct of the centres' activities and adjust accordingly where necessary to improve service delivery.
\end{abstract}

Index Terms-Education, learning management system, LODLC, open learning, distance learning, LAUTECH.

\section{INTRODUCTION}

Open and Distance Learning (ODL) has grown from being a simple correspondence mode of learning to highly sophisticated and interactive teaching and learning alternative [1] and [2]. However, the quality of teaching and knowledge administered via the DL mode remains an issue of discussion among academics. Interestingly, most DL

Manuscript submitted March 18, 2021; revised June 23, 2021.

A. T. Akindele is with Ladoke Akintola University of Technology (LAUTECH), Open and Distance Learning Centre, Ogbomoso, Nigeria (e-mail: atakindele@lautech.edu.ng).

N. O. Akande is with Landmark University, Omuaran, Kwara State, Nigeria (e-mail: akande.oluwatobi@gmail.com).

M. O. Fajobi, H. B. Olagoke, and O. A. Ajagbe are with LAUTECH, Open and Distance Learning Centre, Ogbomoso, Nigeria (e-mail: mofajobi@lautech.edu.ng, oaajagbe23@lautech.edu.ng).

T. A. Badmus is with Federal University Oye-Ekiti, Ekiti State, Nigeria (e-mail: taofeeq.badmus@ fuoye.edu.ng). students have at one time or the other engaged in face to face mode of learning, hence, could be in the best position to compare and contrast between the two modes of learning.

The proliferation of online education platforms is now on the increase with virtually most tertiary institutions in the world about to embark or already started their student-centered distance learning programmes. It is not only educational institutions that are tapping into this initiative but also organisations and individual who are piggybacking on the flexibility and lack of geographical limitations of distance learning as it pertains to four-walls of classrooms. LAUTECH is at the forefront of all other universities in Nigeria and is one of the dominant players in Africa with her innovative technology-enhanced blended model of engaging and facilitating learners in both synchronous and asynchronous learning modes.

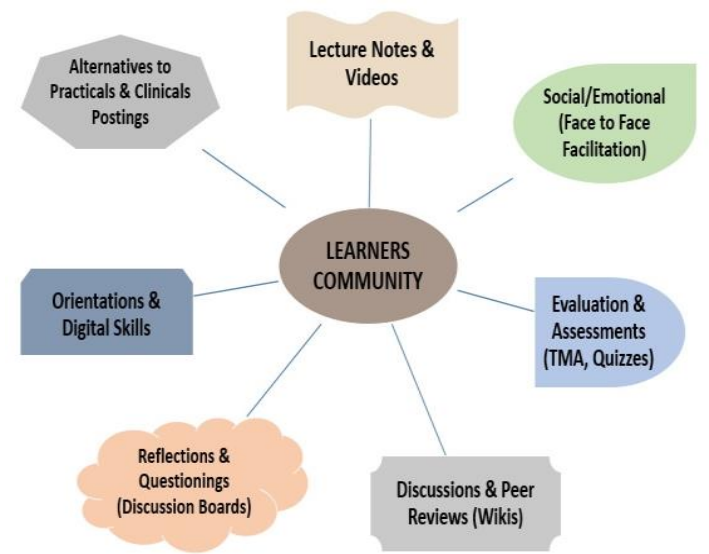

Fig. 1. LODLC blended learning community and its activities.

LODLC operates a blended learning model of ODE. E-tutors are the principal demonstrators and guides on the side for academic instructions concerning the contents in the course materials developed using the proposed method suggested in [3]. They are required to upload reference or lecture materials in multimedia and text format to the centre's Learning Management System (LMS). Survey datasets obtained by LODLC revealed the willingness of learners in using Social Media for continuous engagement and Information Dissemination [4], [5]. Thus, LODLC learners get automated SMS and WhatsApp alerts before online facilitation schedules. At the scheduled time, learners would interact with e-tutors in a real-time text-based or audiovisual virtual classroom. E-tutors engage learners online using modules and activities (Chats, Tutor Mark Assignment (TMA), Discussion Board, Big Blue Button, Forum, or Collaborative Wikis) provided in the LMS. In addition to the 
LMS, Social Media like WhatsApp and Telegram are used to complement the LMS activities to create an environment for the learners to interact socially with their facilitators and with one another. Recently, with increased acceptance of Zoom as the Video Conferencing Platform, LODLC integrated Zoom to our LMS Activities for Video based interaction between learners and all ODE actors. The LODLC blended learning community and the activities involved are shown in Fig. 1.

\section{LEARNING MANAGEMENT SYSTEM AND ITS FEATURES}

LMS is a software application that is used to administer, document, track, report, and deliver educational courses and train learners [6]. LMS plays a crucial role in teaching and learning pedagogy, access and flexibility, and cost-effectiveness in higher education and it is suggested for higher education institutions to integrate the LMS into teaching and learning process in order to achieve effective learning outcomes [6].

LMS is the major ICT infrastructure on which LODLC activities are conducted. On this platform, teaching activities using chats, quizzes, assignments and forum interactions are being administered. Course materials in textual documents and multimedia file uploads could also be distributed via the LMS. In addition to these, students' performance and assimilation can also be tracked and evaluated on the LMS via quizzes and learners' feedback. Besides these, LMS could be used to generate comprehensive reports that could be used to track the activities of students and tutors as well as other support staff. Activities such as rate of course subscriptions and completions, active courses, most accessed courses, time spent on courses, assessment scores, user activity reports, last access by the user, etc. Furthermore, LMS perfectly fits into the concept of Bring Your Own Device (BYOD) that permits the use of new generation of smartphones, tablets and phablets as well as desktop and laptop computers to access its contents [7].

The LMS used on the LODLC platform is the MOODLE. MOODLE is an acronym for Modular Object-Oriented term Developmental Learning Environment. A bibliometric analysis of the use of LMS carried out by [7] and [8] revealed that Moodle's LMS is the most widely adopted open-source LMS platform while WebCT (Blackboard) is the most widely adopted commercial LMS platform. One significant advantage of Moodle that is undoubtedly responsible for its full acceptance is the open-source feature that has made it possible for any user to customize and extend the functionalities to meet their desired expectations. LODLC maximized this opportunity but also enhanced the Moodle's LMS features with APIs and plugins such as big-blue-button for web conferencing, online programming language compilers, online/remote proctored examinations monitoring features, etc. An in-house examination monitoring application that uses vision, gait and audio analysis that leverages on the webcam and audio recorder of laptops was designed to remotely monitor learner' face, head and body movements as well as sounds emanating from their environment during the conduct of online proctored examinations. A comparison of the features present in regular Moodle, Blackboard and Moodle's LMS adapted by LODLC is provided in Table I.

TABLE I: LMS FEATURES COMPARISON

\begin{tabular}{llccc}
\hline S/N & FEATURES & MOODLE & BLACKBOARD & $\begin{array}{c}\text { LODLC } \\
\text { LMS }\end{array}$ \\
\hline 1. & $\begin{array}{l}\text { Survey } \\
\text { Forms }\end{array}$ & Yes & Yes & Yes \\
2 & $\begin{array}{l}\text { Virtual } \\
\text { Classroom }\end{array}$ & No & Yes & Yes \\
3 & $\begin{array}{l}\text { Programming } \\
\text { Compilers }\end{array}$ & No & No & Yes \\
4. & Chat & Yes & Yes & Yes \\
5. & Reports & Yes & Yes & Yes \\
6. & Multimedia & Yes & Yes & Yes \\
7. & Exam & No & No & Yes \\
8. & Donitoring & & Yes & Yes \\
9. & Quiz/Tests & Yes & Yes & Yes \\
\hline
\end{tabular}

At LODLC, practicals for basic science courses are conducted using the alternative-to-practical mode which, when combined with the aid of self-instructional learning materials achieved the objectives of real practical sessions. A typical example for Introductory Physics alternative practical is the Phet Interactive Simulations, an open educational resource created by Carl Wieman in 2002 at the University of Colorado Boulder (https://phet.colorado.edu/). The same alternative to practical model applies to other science-based practical courses. In addition to this, the Centre organized a contact-cum-practical session for the face-to-face facilitation in which participation is mandatory and graded accordingly.

The incorporation of programming compilers into Moodle's LMS is a necessity for Computer Science learners to have strong computer language programming skills. This made it easier to conduct practical sessions for programming classes like Pascal, C, C++, C\#, Java and Python without a need for the students to install such applications on their devices and they can be graded and monitored remotely. This enhanced learner's assimilation as the practicals are being conducted simultaneously with the theoretical learning aspect.

\section{Methodology}

An online survey via the use of Google forms was employed to elicit the perceptions and experiences of LODLC learners about the conduct of her activities. A total number of 2362 LODLC students among the Centre's 5125 learners participated in the survey giving a $46 \%$ response rate. The demographics of the respondents are presented in Fig. 2 and Fig. 3.

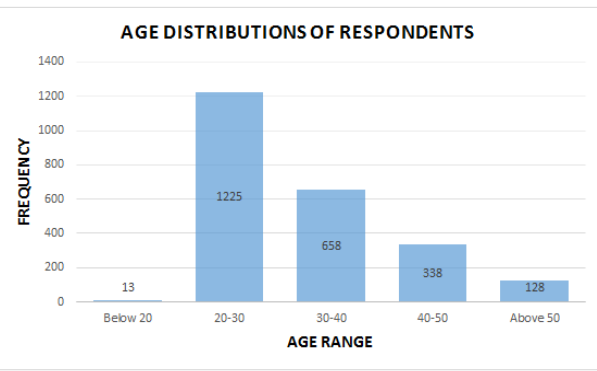

Fig. 2. Age distributions of respondents. 


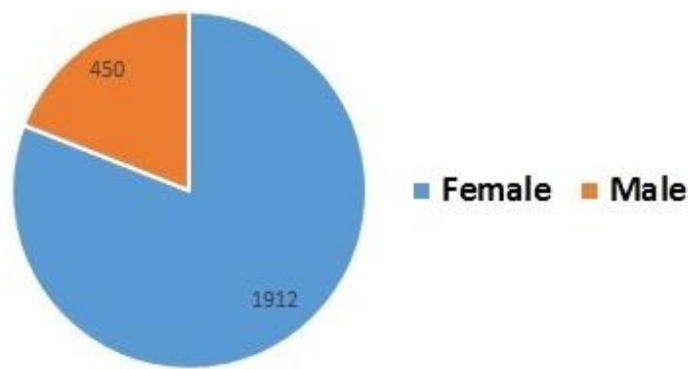

Fig. 3. Respondents' gender ratio.

Furthermore, the study attempted to know students' views about the following research questions:

1) Do learners have access to the online study tools available to them, and how do they use them?

2) Are some tools used online lacking or deficient in imbibing knowledge and why?
3) Do learners feel that these tools enhance and support their learning?

4) Do learners have access to support staffs, on time and were these staffs helpful?

5) Do Learners perceive that LODLC platform is equivalent to or better than the face-to-face mode in the acquisition of knowledge and digital skills?

\section{A. Learners' Responses}

The experiences and perception of learners collated from the questionnaire as it relates to the questions asked are displayed in Table II to Table $\mathrm{V}$ and the analysed responses are depicted in Fig. 4 to Fig. 7.

TABLE II: EVALUATION OF ACADEMIC CURRICULUM AND LECTURE NOTES

\begin{tabular}{|c|c|c|c|c|c|c|}
\hline & $\begin{array}{c}\text { Excellent } \\
(\%)\end{array}$ & $\begin{array}{c}\text { Very Good } \\
(\%)\end{array}$ & $\begin{array}{c}\text { Satisfactory } \\
(\%)\end{array}$ & $\begin{array}{l}\text { Fair } \\
(\%)\end{array}$ & $\begin{array}{c}\text { Poor } \\
(\%)\end{array}$ & $\begin{array}{c}\text { Total } \\
(\%)\end{array}$ \\
\hline Level of the relevance of Curriculum to recent trends in Industries & 9.1 & 19.3 & 23.3 & 46.7 & 1.6 & 100 \\
\hline Level of knowledge impacted for job or work-related & 10.9 & 19.7 & 22.3 & 45.3 & 1.8 & 100 \\
\hline Grammar, Styles and Punctuations of Lecture Notes & 9.7 & 17.3 & 23.2 & 44.5 & 5.3 & 100 \\
\hline Availability of Practical Sessions for Courses offered & 6.4 & 12.3 & 31.3 & 44.3 & 5.7 & 100 \\
\hline $\begin{array}{l}\text { Level of Knowledge \& Experience from Clinicals Postings, } \\
\text { SIWES/SWEP }\end{array}$ & 9.7 & 14.8 & 25.5 & 44.7 & 5.3 & 100 \\
\hline Learning Objectives of Study Sessions were clear and achieved & 14 & 19.6 & 19.9 & 43.3 & 3.2 & 100 \\
\hline Learners Acquisition of ICT skills, Soft Skills and Critical thinking & 11 & 16.9 & 20.6 & 45 & 6.5 & 100 \\
\hline
\end{tabular}

TABLE III: ASSESSMENT OF LODLC LMS AND ONLINE ACTIVITIES

\begin{tabular}{|c|c|c|c|c|c|c|}
\hline & SA (\%) & $\mathrm{A}(\%)$ & $\mathbf{N}(\%)$ & D (\%) & SD (\%) & $\begin{array}{c}\text { Total } \\
(\%)\end{array}$ \\
\hline e-Tutor was an effective demonstrator & 13.6 & 44.2 & 31.9 & 6.5 & 3.8 & 100 \\
\hline Orientation and Awareness is adequate & 15.7 & 41.4 & 31.2 & 6.2 & 5.5 & 100 \\
\hline $\begin{array}{l}\text { E tutors stimulated learners' interest and } \\
\text { answered questions asked satisfactorily }\end{array}$ & 18.4 & 42.3 & 27.5 & 7.2 & 4.6 & 100 \\
\hline LMS is easily accessed and responsive & 13.7 & 32.9 & 26.1 & 18.8 & 8.5 & 100 \\
\hline $\begin{array}{l}\text { Modules and Features of the LMS were } \\
\text { adequate }\end{array}$ & 14.9 & 39.5 & 30.2 & 10.7 & 4.7 & 100 \\
\hline $\begin{array}{l}\text { Accessing and downloading lecture material } \\
\text { from is LMS is Satisfactory }\end{array}$ & 25.4 & 35.0 & 25.9 & 7.3 & 6.4 & 100 \\
\hline $\begin{array}{l}\text { I can check past sessions and reattempt } \\
\text { missed activities }\end{array}$ & 19.0 & 32.6 & 27.0 & 13.1 & 8.3 & 100 \\
\hline $\begin{array}{l}\text { Attempting Quizzes and TMA is smooth and } \\
\text { effortless }\end{array}$ & 15.7 & 33.2 & 26.4 & 17.1 & 7.6 & 100 \\
\hline $\begin{array}{l}\text { Grading of activities was prompt and had } \\
\text { useful feedback }\end{array}$ & 12.9 & 37.6 & 32.0 & 11.9 & 5.6 & 100 \\
\hline $\begin{array}{l}\text { Forums and Discussion between Learners } \\
\text { Only is used adequately }\end{array}$ & 11.3 & 33.7 & 34.5 & 14.1 & 6.4 & 100 \\
\hline
\end{tabular}

TABLE IV: ASSESSMENT OF SOCIAL MEDIA PLATFORM AND SUPPORT STAFF

\begin{tabular}{|c|c|c|c|c|c|c|}
\hline & SA (\%) & $\mathrm{A}(\%)$ & $\mathrm{N}(\%)$ & D (\%) & SD (\%) & Total $(\%)$ \\
\hline $\begin{array}{l}\text { News and Information flow via Social } \\
\text { Media is adequate }\end{array}$ & 19 & 35.2 & 30.2 & 9.3 & 6.3 & 100 \\
\hline $\begin{array}{l}\text { Responses to Complaint and Queries is } \\
\text { Prompt and satisfactory }\end{array}$ & 13.4 & 32.6 & 31.1 & 14.1 & 8.8 & 100 \\
\hline $\begin{array}{l}\text { Orientation and Awareness of program } \\
\text { requirement is adequate }\end{array}$ & 15.7 & 41.5 & 28.1 & 9.2 & 5.5 & 100 \\
\hline $\begin{array}{l}\text { Support Staffs are readily accessible and } \\
\text { helpful }\end{array}$ & 11.2 & 34.4 & 41.6 & 8.2 & 4.6 & 100 \\
\hline
\end{tabular}




\begin{tabular}{|c|c|c|c|c|c|c|}
\hline & SA $(\%)$ & A $(\%)$ & $\mathbf{N}(\%)$ & $\mathrm{D}(\%)$ & SD (\%) & Total $(\%)$ \\
\hline $\begin{array}{l}\text { Facilitators Interactions is clear and } \\
\text { compliant to topics discussed online }\end{array}$ & 11.6 & 39.1 & 39.4 & 5.8 & 4.1 & 100 \\
\hline $\begin{array}{l}\text { Exam Questions and Time allocated is } \\
\text { Satisfactory }\end{array}$ & 8.1 & 27 & 40.3 & 16.3 & 8.3 & 100 \\
\hline $\begin{array}{l}\text { Exam Results are easily accessible and } \\
\text { prompt }\end{array}$ & 8.8 & 27.6 & 42.4 & 14.2 & 7 & 100 \\
\hline $\begin{array}{l}\text { Exam Conditions \& Supervision is } \\
\text { satisfactory }\end{array}$ & 10.5 & 30.1 & 43.3 & 10.3 & 5.8 & 100 \\
\hline $\begin{array}{l}\text { Exam Result performance is reflective of my } \\
\text { preparation }\end{array}$ & 9.6 & 29 & 44.8 & 9.9 & 6.7 & 100 \\
\hline
\end{tabular}

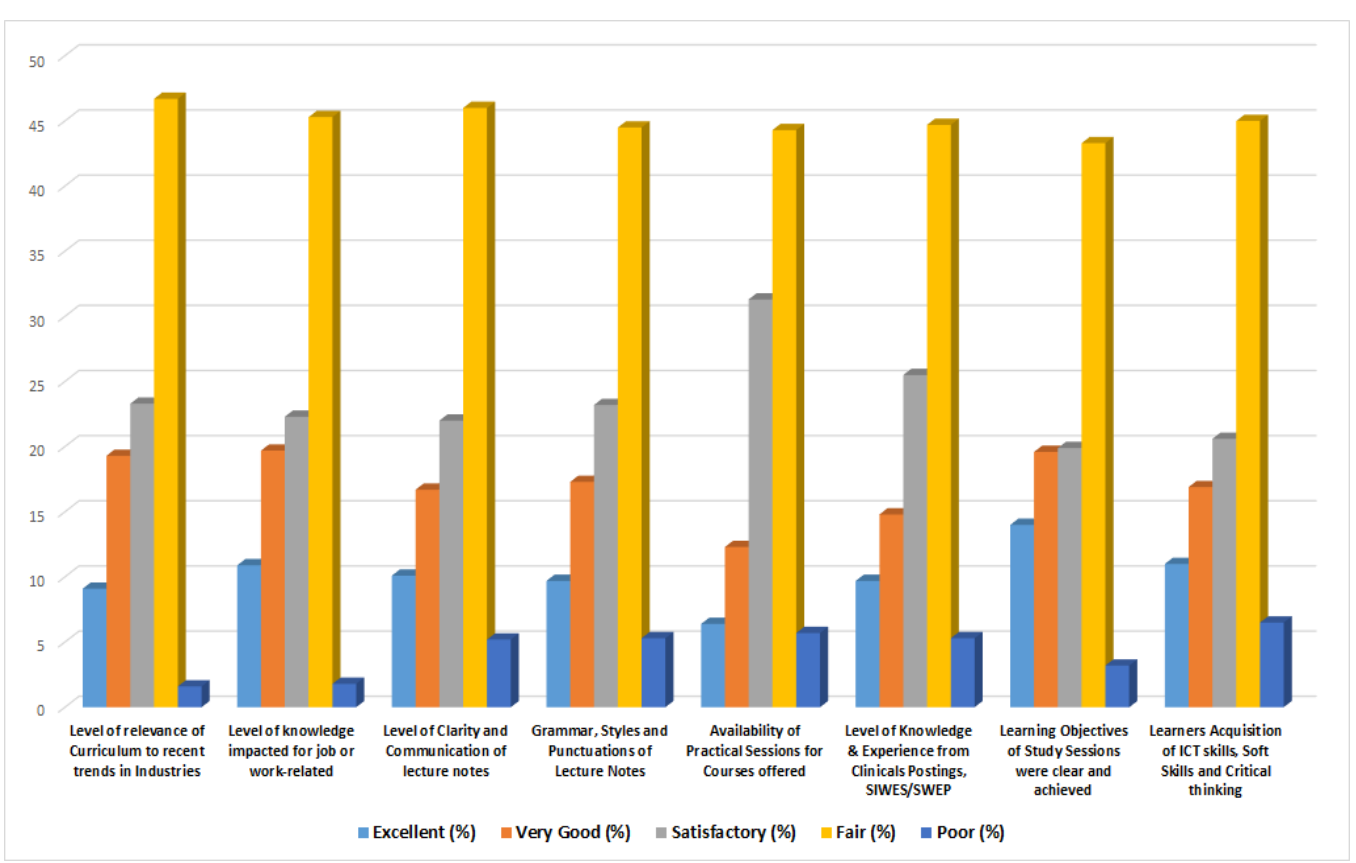

Fig. 4. Evaluation of academic curriculum and lecture notes.

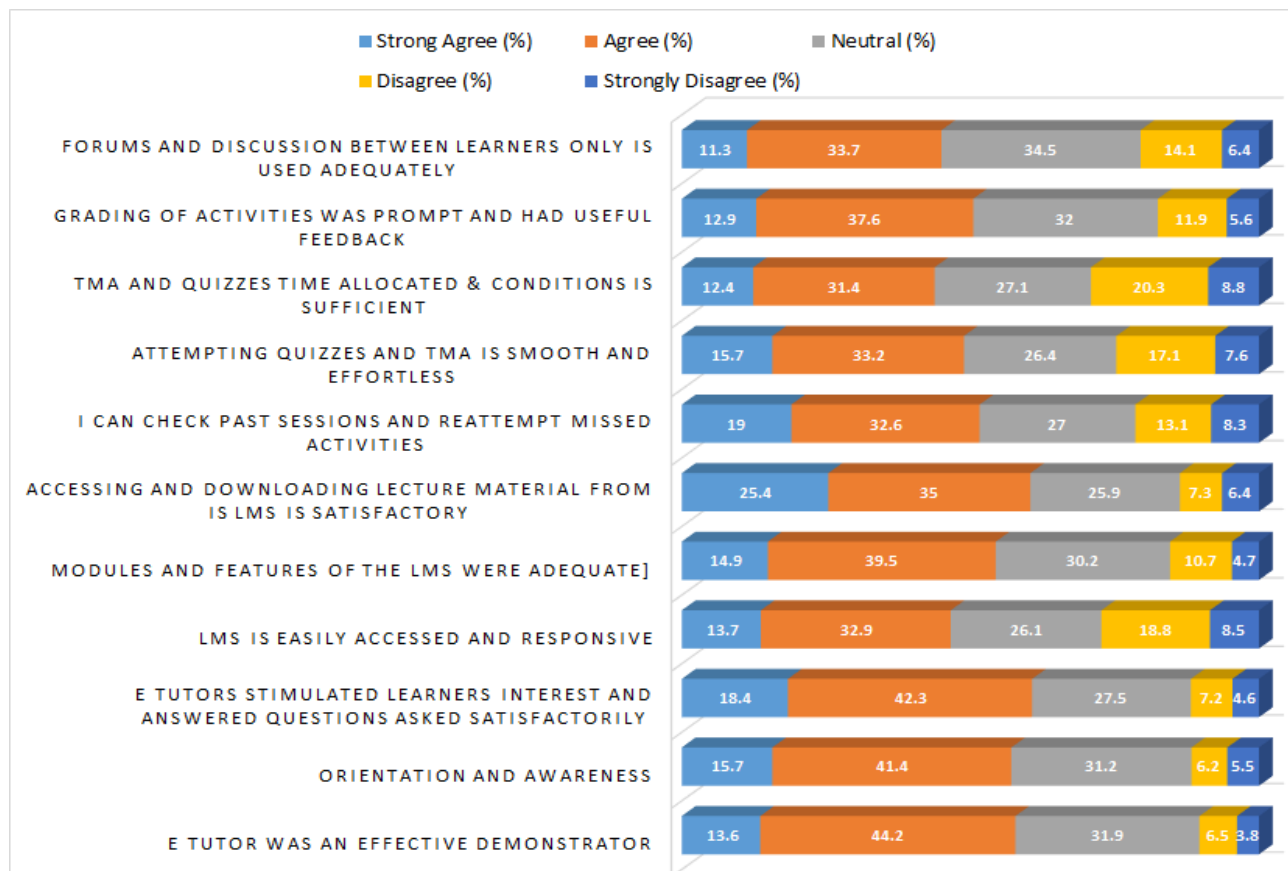

Fig. 5. Assessment of the LMS and online activities. 


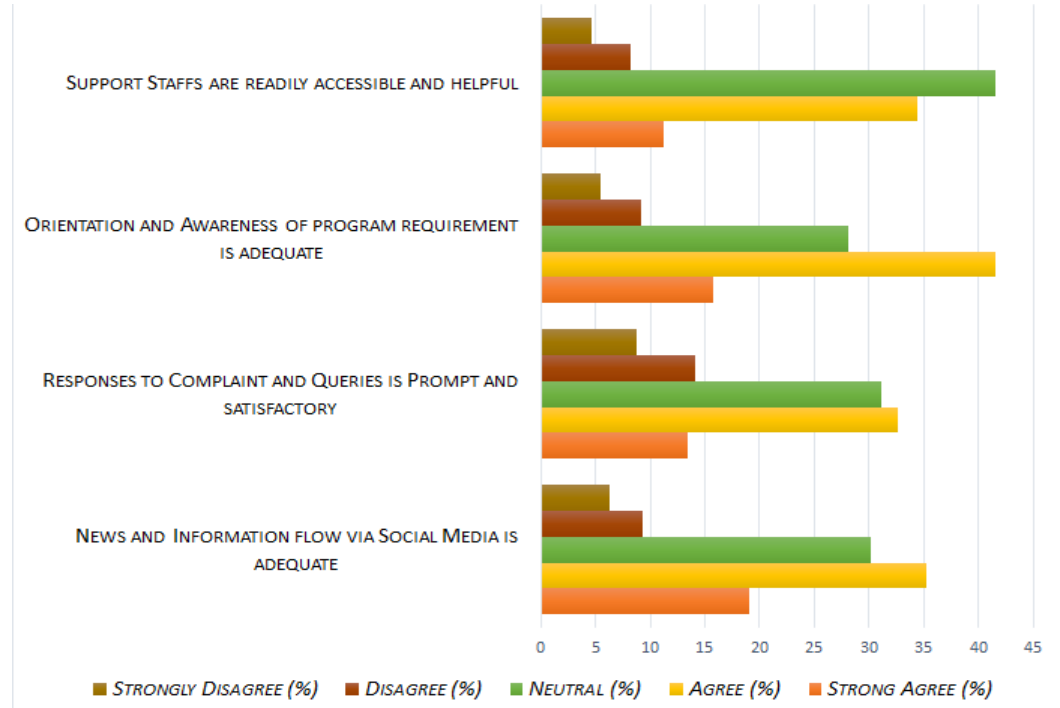

Fig. 6. Assessment of social media platform and support staff.

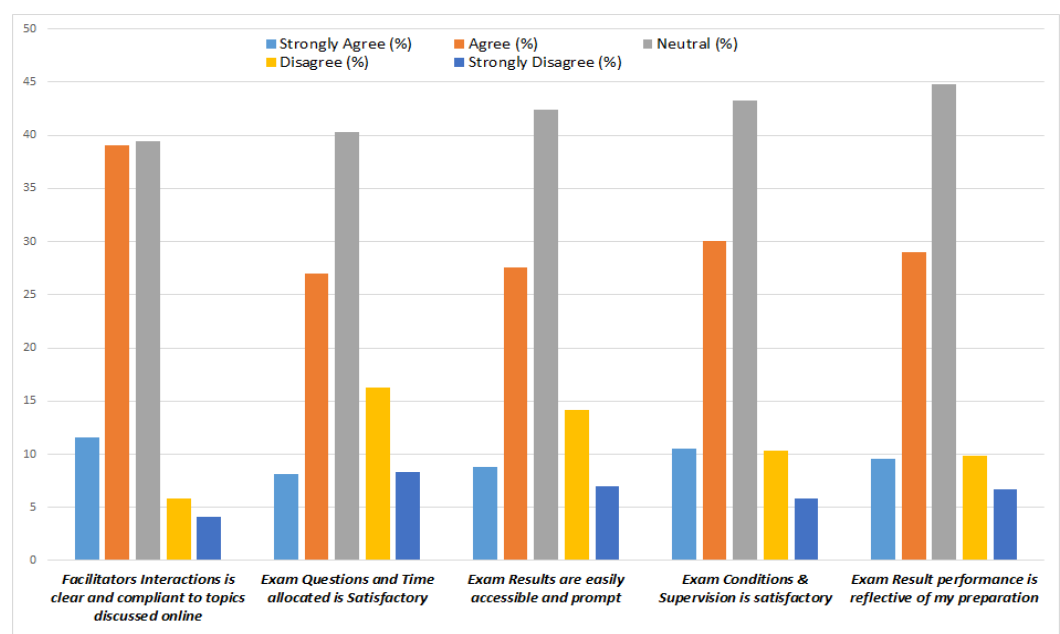

Fig. 7. Chart of the learners' perception of Examinations and face to face facilitation.

\section{RESUlt AND DisCUSSIONS}

As presented in Table I to Table $\mathrm{V}$, the research questions are in four (4) categories. Since the students were given a student's handbook that contains a breakdown of what they are to learn per semester, the first category of questions attempts to know the students' perspectives about the academic curriculum and lecture notes. To some extent, students can also measure if what is being taught conforms with what is in the curriculum. They could also adjudge if the contents of the lecture notes align with what is in the curriculum.

As shown in Fig. 4-Fig. 7, 49\% of the respondents adjudge the contents of the lecture notes to be clear and concise, while $46 \%$ believed that it is fair. $53 \%$ of the respondents believed that the learning outcomes of each study sessions of the lecture notes were met while $43 \%$ adjudged them to be fair. The students' view about the LMS and online activities, in general, were also elicited with the second category of questions. Responses received revealed that $46 \%$ believed that the LMS is easily accessible and responsive while $27 \%$ disagreed. Concerning the adequacy of the features and modules of the LMS, $54 \%$ claimed they are adequate while $16 \%$ claimed the features are inadequate. Excitingly, $60 \%$ of the respondents could easily access and download course materials from the LMS while $49 \%$ believed that Tutor Marked Assessment (TMA) and quizzes could be done effortlessly and smoothly. Similarly, $51 \%$ could review past interactive sessions and re-attempt missed activities. Furthermore, $57 \%$ of the respondents rated the e-tutors to be a capable and practical demonstrator while $60 \%$ believed the e-tutors stimulated learners' interest by providing satisfactory answers to questions asked. When the respondents were asked about the time allocated to the TMA's and quizzes, $43 \%$ believed the time was sufficient $20 \%$ disagreed. In the same vein, $50 \%$ of the respondents believed that grading of activities was prompt and had useful feedbacks, while $44 \%$ believed that interactions among students via chats and forums helped a great deal.

To ensure effective dissemination of information, social media platforms such as WhatsApp, Facebook and Telegram were adopted. However, WhatsApp was the main medium for social interaction. Every level has dedicated WhatsApp groups for interaction. In addition to this, there are dedicated Learners Support Staff (LSS) that ensures that students complaints are promptly attended to. Students' view about the use of social media and the activities of the learner support staff were also evaluated. 54\% of the respondents believed that information flow via social media is sufficient and adequate; only $9 \%$ disagreed. $69 \%$ also adjudged that 
learner support staff's response to enquiries and complaints is satisfactory. Overall students' performance needs to be measured via the conduct of examinations. Though the mode of learning is open, examinations are not fully online. However, in exceptional cases for international students, examinations could be conducted online. If examinations are conducted online, an in-house student gesture tracking application software that has been integrated into the LMS was used to monitor the students and their environment. The application tracks the student's head and body movement as well as sounds emanating from the student's environment. Other students are expected to come down to the centre for a week face to face facilitation which serves as a revision period. Examinations are mostly paper and pen-based with some being computer-based. Students' view about the conduct of the examination as well as the face to face contact period were also elicited. $49 \%$ of the respondents submitted that topics discussed during facilitation conform to those discussed online. $38 \%$ also believed that examination condition is conducive and satisfactory. $33 \%$ also were satisfied with the time allotted to exam questions.

\section{CONCLUSION}

ODL has come to stay as a viable alternative mode of learning. Its increasing acceptability across Universities in Nigeria confirms this conjecture. With a geometric increase from 236 students and one programme in 2015 to 5125 students and 6 programmes presently, the need to assess learners' perception of the conduct of the centre's activities is imperative. The feedback received will help the centre in her policy and decision making as more students are enrolling and more programmes are established in the centre. Though 2362 of the centre's 5125 students participated in the survey, responses received were beneficial in deciding areas that need to be reviewed and those that need to be sustained. The overall survey, which revealed an increasing number of enrollments every academic session implies an increased acceptance rate of ODL as an alternative means of furthering one's education. However, the responses of the learners in regards of the learning activities also inferred that the LMS and its modules together with other technologies employed needs more fine tuning efforts and better resources to make the learning process more accessible, flexible and smooth for the learners. he results of this paper revealed that OERs are increasingly playing an indisputable and fundamental role in education for both faculty and learners. Interestingly, sharing educational resources openly and with no admission fee has ideological and financial justifications which creates a major demand for clarifying fundamental questions, such as who are the stakeholders in these processes, in what way are they involved and why, and how do they influence the development, use, and widening of OERs? However, print educational materials are tailored to address the educational needs of Nigerian students depending on the laid down objectives of the given institution and it is largely upon which the implementation of the national curriculum depends. The infrastructural decay of the print sections and the paradigm shift of the learning interest of the students is keeping them off the print section's register. The growing IT infrastructures, ease of access and current contents and proximity associated with OER have made it an educational hotcake [9]. Though print stocks still remain relevant, their contribution to educational dispensation in Nigeria is still unsatisfactory.

\section{CONFLICT OF INTEREST}

The authors declare no conflict of interest.

\section{AUTHOR CONTRIBUTIONS}

A. T. Akindele and N. O. Akande conducted the research; T. A. Badmus and H. B. Olagoke, edited and reviewed the paper; M. O. Fajobi and O. A. Ajagbe gathered the data; M. O. Fajobi and N. O. Akande, analyzed and interpreted the data; T. A. Akindele wrote the final version of the paper and effected review comments. All authors discussed progress and results of the research and approved the final version.

\section{ACKNOWLEDGEMENT}

The authors thank and acknowledge the management of Ladoke Akintola University of Technology, Nigeria most especially the Director, LODLC (Prof. O. T. Arulogun) for the support and approval to conduct this research using the isntitution's Open and Distance Learning Centre as a case study. Authors also appreciate the honest responses of the centre learners, whose responses constitute the perceptions and experiences as analysed in this study.

\section{REFERENCES}

[1] C. Vrasidas, "Constructivism versus objectivism: Implications for interaction, course design, and evaluation in distance education," International Journal of Educational Telecommunications, vol. 6, no. 4, pp. 339-362, 2000.

[2] C. Vrasidas and G. V. Glass, "A conceptual framework for studying distance education," Current Perspectives in Applied Information Technologies: Distance Education and Distributed Learning, pp. 31-56, Greenwich, CT: Information Age Publishing, Inc., 2002.

[3] O. T. Arulogun and A. S. Gbadegesin, "Towards achieving an effective courseware development for open and distance education: LAUTECH experience," presented at 26th Conference of the International Council for Open and Distance Education (ICDE), Sun City, South Africa, 14-16 October 2015

[4] O. Akande, T. Badmus, A. Akindele, and O. Arulogun, "Dataset to support the adoption of social media and emerging technologies for students' continuous engagement," Data in Brief, vol. 31, p. 105926, 2020 .

[5] O. Arulogun, O. Akande, A. Akindele, and T. Badmus, "Survey dataset on open and distance learning students' intention to use social media and emerging technologies for online facilitation," Data in Brief, vol. 31, p. 105929, 2020.

[6] A. Chaubey and B. Bhattacharya, "Learning management system in higher education," International Journal of Science Technology \& Engineering IJSTE, vol. 2, no. 3, pp. 158-162, ISSN (online): 2349-784X, 2015.

[7] H. Chowdhury and A. Kootsookos, "Utilization of learning management systems (LMSs) in the higher education system: A case review for Saudi Arabia education system," Energy Procedia, vol. 160, pp. 731-737, 2019

[8] F. Soykan and S. Burak, "Examining studies on learning management systems in the SSCI database: A content analysis study," Procedia Procedia Computer Science, vol. 120, pp. 871-876, 2018.

[9] A. Qayyum and O. Zawacki-Richter, "The state of open and distance education," Open and Distance Education in Asia, Africa and the Middle East, Springer, Singapore, 2019.

Copyright (C) 2021 by the authors. This is an open access article distributed under the Creative Commons Attribution License which permits unrestricted use, distribution, and reproduction in any medium, provided the original work is properly cited (CC BY 4.0). 


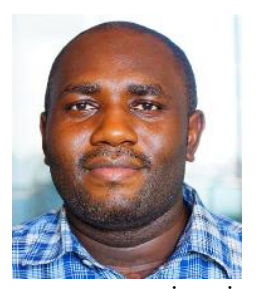

Akinyinka Tosin Akindele is an instructional designer and one of the pioneer etutors of LAUTECH Open and Distance Learning (LODLC), Nigeria, where he has worked since 2014 till date. He also served as an elearning consultant for Kampala International University, Uganda. His academic qualification includes a master of technology in computer science and bachelor of technology in computer engineering from Ladoke Akintola University of Technology, Nigeria. He is presently pursuing his $\mathrm{PhD}$ from same institution. In addition to elearning, his research areas include computer vision, natural language processing, fuzzy logic, bioinformatics, data science and the applications of artificial intelligence (AI) to health, education and transportation.

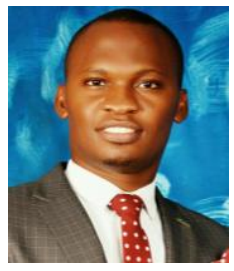

Noah Oluwatobi Akande had his first and second degrees from Computer Science and Engineering Department of Ladoke Akintola University of Technology, Ogbomoso, Nigeria. Afterwards, he had his $\mathrm{Ph} . \mathrm{D}$ degree in computer science from Computer Science department, University of Ilorin. He has passion for problem oriented researches and has focused on data and information security, e-learning technologies and biomedical image analysis. He has several publications in local and international conferences as well as local and SCOPUS indexed international journals. He belonged to several professional bodies such as Computer Professionals on Nigeria (CPN), Nigeria Computer Society (NCS) and IAENG society of computer science.

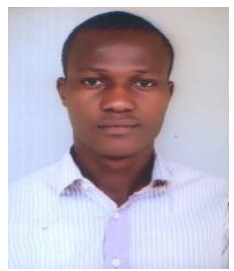

Moses Oluwatobi Fajobi is an academic staff of Ladoke Akintola University of Technology, Open and Distance Learning Centre, Ogbomoso, Nigeria. In 2010 and 2016, respectively, he obtained his B.Tech. (Hons) and M.Tech. degrees in mechanical engineering at Ladoke Akintola University of Technology, Ogbomoso, Nigeria. Presently, for his $\mathrm{Ph} . \mathrm{D}$., he is researching energy extraction rom biomass and optimization of the process using artificial intelligence, at University of Ilorin, Ilorin, Nigeria. He is a member, Nigerian Society of Engineers and a registered engineer with the Council for the Regulation of Engineering in Nigeria. His research interest includes the design of optimal processes, evaluation, modelling and simulation. He had since been publishing learned journals or peer reviewed conference.

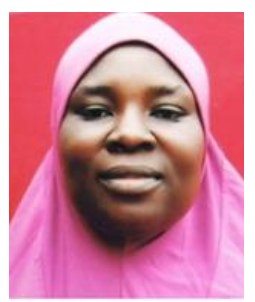

Halima Bukola Olagoke holds BSc. and M.Tech. in industrial chemistry from Adekunle Ajasin University and Ladoke Akintola University of Technology. Nigeria respectively. She also possesses a post-graduate diploma in education (PGDE) and is presently pursing her Ph.D at Federal University, Oye-Ekiti, Nigeria. She works as an eTutor at LAUTECH Open and Distance Learning Centre, Ogbomosho, Oyo State from 2014 till date. She is a member of the Student Chemical Society of Nigeria (SCSN) and Nigerian Association of Petroleum Explorationists (NAPE). Her previous research interest was on the use of agricultural waste in the remediation of waste water. Currently, her research interest is on the use of seed oil in synthesizing polymers.

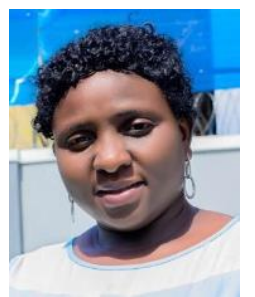

Oluwafemi Adeola Ajagbe holds B.Tech and M.Tech of computer science from Ladoke Akintola University of Technology, Nigeria. She works as an e-tutor at LAUTECH Open and Distance Learning, Ogbomoso, Nigeria. Her areas of research interest include Elearning, data mining, pattern recognition and information systems. She is presently pursing her $\mathrm{Ph} . \mathrm{D}$ at same institution.

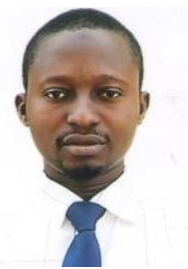

Taofeeq Alabi Badmus is a lecturer in the Department of Computer Engineering, Federal University, Oye-Ekiti, Nigeria. He graduated with a B.Tech. degree in computer engineering from Ladoke Akintola University of Technology (LAUTECH), Ogbomoso, Nigeria, in 2011. Also, he obtained M.Tech. degree in computer science from LAUTECH in 2018. He is currently a Ph.D student in the Faculty of Engineering, University of Nottingham, United Kingdom. His research interests include e-learning/ODL teaching and learning modes, system modelling and simulation as well as reliability engineering. 